\title{
La oralidad y el contexto cultural en la poesía de Jaime Gil de Biedma
}

\author{
DOUGLAS K. BENSON \\ Kansas State University
}

Jaime Gil de Biedma, a pesar de su escasa producción y de su renuncia al oficio de poeta en años recientes, posee una fama que parece extenderse con cada generación nueva de lectores y poetas. Se siguen publicando nuevas ediciones de su obra completa ${ }^{1}$ y nuevos libros críticos importantes como los de Shirley Mangini González (1980) y Pere Rovira (1986)². Mangini González lo llama «el modelo de tonos de su generación» ${ }^{3}$; en cambio, José Olivio Jiménez nota la "franca admiración y respeto" evidenciados en los poetas jóvenes de los 70, «por lo común orientados en sus temas y lenguaje hacia rumbos estéticos bien diferentes a los de Gil de Biedma». Varios poetas

1. Jaime Gil de Biedma publicó cinco libros de poesía entre 1953 y 1968; la mayoría de estos poemas (el poeta ha omitido algunos) aparecen en Las personas del verbo (Barcelona, Seix y Barral, 1982). Además de una reorganización sustancial de los poemas del último de los cinco libros, Poemas póstumos, la edición contiene unos cuantos poemas más escritos hasta 1981. Pero Gil de Biedma efectivamente dejó de escribir poesía en los 60; véase Gracia Rodríguez, «El oficio de escribir: entrevista con Jaime Gil de Biedman, Quimera, n. 32 (octubre 1982), 49.

En el presente estudio los poemas citados vienen de la edición de Seix Barral de 1982.

2. Shirley Mangini González, Jaime Gil de Biedma (Madrid, Júcar, 1980); Pere Rovira, La poesía de Jaime Gil de Biedma (Barcelona, Ediciones del Mall, 1986).

3. Mangini González, 71.

4. José Olivio Jiménez, «Una versión realista de la irrealidad: sobre Jaime Gil de Bied- 
de las últimas dos décadas han documentado en su crítica la importancia de Gil de Biedma para sus generaciones ${ }^{5}$. José Luis Giménez Frontín estudia más detalladamente su influencia tanto en los poetas «sociales» como en los «novísimos», confirmando la opinión de González Muela de que Gil es el único poeta de postguerra que atrae a ambos grupos ${ }^{6}$. La crítica comenta en su obra aspectos tan diversos como sus innovaciones en el uso del lenguaje "coloquial», la vasta cultura evidente en sus alusiones literarias, la manera en que su lenguaje "realista" sirve para mostrarnos la "irrealidad" de nuestra vida, y el papel de la ilusión como elemento clave en ella ${ }^{7}$.

Una de las facetas más comentadas de su obra como característica de la postguerra es el virtuosismo con el que Gil integra elementos orales a su estructura poética. Claro está, el uso de lo oral en la poesía no comienza ni con Gil ni con su generación de la postguerra; podemos encontrar ejemplos en poetas tan diversos como Campoamor, Lorca y el Alberti "comprometido". Varios críticos suelen señalar a Dámaso Alonso, y el lenguaje coloquial de su famoso libro Hijos de la ira (1944), como el modelo de la ruptura con la poesía "oficial» de la postguerra $^{8}$. Después de Alonso, los poetas de la postguerra inmediata son los que se dedican con más fervor a su desarrollo.

Pero a menudo por razones popularizantes e ideológicas estos poetas de los cuarenta y cincuenta adoptaron elementos orales en

ma y su libro Moralidades (1966)», en su libro Diez años de poesía española: 1960-1970) (Madrid, Insula, 1972, págs. 205-221). Las citas vienen de las páginas 206-208.

5. Véanse, por ejemplo, Pere Gimferrer, «La poesía de Jaime Gil de Biedma», Cuadernos Hispanoamericanos, n. ${ }^{\circ} 202$ (octubre 1966), 240-245; Juan Antonio Masoliver Ródenas, "El don de la elegia", Camp de l'Arpa, 35-36 (agosto-setiembre 1976), 12-24; y José Luis Giménez Frontín, «Entre sociales y novísimos: el legado poético de Jaime Gil de Biedma", Quimera, n. 32 (octubre 1982), 52-63. Masoliver comenta en detalle la trayectoria temática de su obra.

6. Giménez Frontín, 53-63; Joaquín González Muela, La nueva poesía española (Madrid, Alcalá, 1973), pág. 82.

7. Consúltense Mangini González, 17-22, 32-34 y 36-57; José Olivio Jiménez, 205-215; Andrew P. Debicki, "Jaime Gil de Biedma: the Theme of Illusion", en su libro Poetry of Discovery: the Spanish Generation of 1956-71 (Lexington, University Press of Kentucky, 1982), págs. 123-29; Pere Rovira, 142-45, 175-99 y 247-57; y Margaret H. Persin, «Intertextual Strategies in the Poetry of Jaime Gil de Biedma", Revista Canadiense de Estudios Hispánicos, en prensa.

8. Véanse Rovira, 28-29; Mangini González, 10; y Santiago Daydi-Tolson, «Aspectos orales de la poesía social española de posguerra", Hispanic Review, 53 (1985), 449-466 (su comentario sobre Alonso está en la página 457). 
gran escala, muchas veces en su forma más coloquial. Intentaban así "reproducir en sus obras las situaciones del habla diaria en actos de comunicación inmediata" 9 . Claro está, "oral" y "coloquial» no son en todo caso sinónimos. Daydí nota, por ejemplo, que el habla común es sólo una de las formas orales utilizadas por las generaciones de la postguerra. Otras son la tradición de la oratoria y la lengua literariopopular de la tradición de "auténtico carácter oral»" ${ }^{10}$ Además, este deseo de volver a un idioma puramente oral para fines de comunicación popular era imposible de realizar. Por las condiciones políticas de la época de la postguerra, esos poetas no tenían acceso a los medios necesarios para comunicarse directamente con el público en masa; en realidad, las revistas que publicaban sus poesías eran de corta duración y sólo accesibles a un número muy pequeño de lectores selectos ${ }^{11}$. Hoy sólo sobreviven los que pudieron superar esta tendencia de usar la poesía para fines prácticos, y que lograron crear experiencias humanas auténticamente complejas en su obra: Blas de Otero, Jósé Hierro y Gabriel Celaya.

Sabemos, finalmente, que la distinción crítica tradicional entre un tono y lenguaje apropiadamente "poéticos" y otros "cotidianos", entre unas fuentes "escritas" y otras "orales» como bases de la literatura, es falsa ${ }^{12}$.

Margaret Persin señala que la crítica reciente acepta la intertextualidad en su sentido más amplio: el procedimiento por el que un escritor utiliza trozos de lenguaje previos, sean literarios o no, para enriquecer su texto. Es el contexto cultural entero, y no sólo el texto específico aludido, lo que prepara los significados que resultan del estímulo ${ }^{13}$. John Ellis extiende el concepto aún más allá en su evaluación

9. Daydí, 450-51.

10. Ibid, 456.

11. Ibid, 453-460.

12. Daydí, 450; Rovira, 20. Debicki estudia extensamente cómo los elementos orales y escritos se modifican en la obra de Gil de Biedma, mientras que John Ellis rechaza en toda la literatura la diferencia entre un estilo "literario" y otro que no lo es, en The Theory of Literary Criticism: A Logical Analysis (Berkeley, University of California, 1974), págs. 12-27 y 173-176. Y Angel González respondió a la pregunta «¿Hay una diferencia entre fuentes literarias y fuentes orales cuando Ud. desarrolla sus temas y estructuras poéticas? de esta manera: «Ninguna». (Entrevista, Lawrence, Kansas, 2 de abril de 1987).

13. Persin, "Intertextual Strategies». Véase la nota 7 de su artículo, donde se cita a Jonathan Culler al delinear éste la misma conexión cultural de la intertextualidad que comento a continuación en Ellis. 
de la interpretación crítica que se basa en información histórica sobre la época de producción del texto:

\begin{abstract}
A better and more relevant distinction here is that between the shared meanings and associations of words in the linguistic community, on the one hand, and the local features of the original context of the composition of the text on the other. This distinction focuses the issue in a more useful way than does that between "textual" and "extratextual", and it allows us to see that ignoring what is "extratextual" (in the historicist's sense) is by no means to take the text in isolation; on the contrary, it is to refer it to a wider context, and even to use more information to interpret it.

The problem of allusion, for example, is much more easily dealt with in this framework; biblical allusions can be a meaningful part of a literary text only because the Bible is part of the shared experience of a given community, not because the author of that text in particular has read it. Cultural allusions, too, must be viewed as part of the stock of the linguistic community, and so must allusions to historical situations that are sufficiently part of the consciousness of the community to present distinct images to its members. That is to say, the details of historical fact may not be relevant, but any part of history that has become in a sense legendary will be part of the available stock of the community's shared ideas, and therefore part of its system of communication ${ }^{14}$.
\end{abstract}

Por lo tanto, podemos ver ya que los poetas de la segunda generación de la postguerra, la de Gil de Biedma, llegaron a otro destino mediante los mismos recursos. Adoptaron un lenguaje poético que evocaba la apariencia de coloquialismo, no el coloquialismo mismo que originalmente se buscaba, y al hacerlo gradualmente convirtieron este y otros muchos recursos apropiados a sus inmediatos antecesores en una nueva convención literaria ${ }^{15}$.

Rovira nota que es difícil que los poetas escriban de lo que no conocen (como los poetas del cincuenta querían integrarse, por ejemplo, a la vida de los obreros). Por consiguiente, muchos de los de la segunda generación de la postguerra volvieron a preocuparse por su propia clase social: la burguesa en su contexto urbano ${ }^{16}$. Y es en este contexto donde vienen las verdaderas innovaciones de Gil de Biedma, Angel González, Gloria Fuertes, José Angel Valente y Francisco Brines. Estos poetas tomaron elementos orales y otros recursos que

\footnotetext{
14. Ellis, 140-142.

15. Daydí, 460.

16. Rovira, 33-40.
} 
la poesía había desarrollado anteriormente de una manera más dispersa, y con ellos van creando un denso arsenal de voces y de miras inusitado en la poesía española hasta entonces.

Por ejemplo, logran caracterizar a sus hablantes mediante la reproducción del modo muy personalizado de su pensar, algo semejante al «flujo de conciencia» en la narrativa o el "monólogo dramático» tanto en boga con los poetas ingleses, pero aplicado a las circunstancias sociales y psicológicas de la situación española ${ }^{17}$. Este enfoque personalizado, a su vez, permite una experiencia compleja y rica para el lector, una experiencia que depende mucho de su interpretación de las perspectivas puestas en yuxtaposición por los hablantes. Como señala Rovira, la anécdota o situación tan evidente en la poesía de Gil de Biedma es sólo el punto de partida para que experimentemos los juicios personales, a menudo ambiguos, de un hablante ficticio pero muy concreto. Por lo tanto, el aspecto social ahora viene mediante la voz que lo contempla y no por el tema. La voz personal no se subordina a los topoi, como en la poesía clásica, ni a los vuelos subjetivos de la imaginación, como en el romanticismo o el surrealismo, ni a una estilización de la realidad como la ejecutada por la generación del 27, ni a la situación social, como en los cincuenta. "No se trata de admirar al lector y de arrastrarle con hábiles choques verbales, sino de situarle ante alguien ${ }^{18}$.

Por eso, en Gil de Biedma (como en González, Fuertes o el Brines tardío) presenciamos tantas voces diferentes, a menudo dentro de un solo poema. En Gil ya se ha comentado la voz más característica, la del lenguaje cultivado de un joven capitalista rico ${ }^{19}$, pero se ha señalado en su obra también lenguaje típico de las "palabras de familian; del pensar de la adolescencia, de la madurez, y de la vejez; de las profesiones; del chisme callejero; de la relación íntima amorosa; de la tertulia; y en función irónica, de la oratoria ${ }^{20}$.

17. Mangini González, 42-47 y 62-67; Rovira, 76-79. Rovira nota que esta voz personalizada en función dramática, lo que los poetas ingleses denominan "poesía de experiencia» (Wordsworth, Coleridge), es para Gil «la genuina y característica poesía moderna” (pág. 63).

18. Rovira, 37-43, 78, 96 y 138-139. Este crítico nota que en los poemas sociales deliberados de Gil este tono de una voz en lucha consigo misma se traiciona, y son por lo tanto muy inferiores a sus poemas más característicos (135).

19. González Muela, 102-103.

20. Masoliver, Giménez, Rovira, Debicki y Mangini González son los críticos que con más esmero se han preocupado por esas voces y tonos. 
Lo curioso es que, al examinar las incidencias de lenguaje "coloquial» que le creó tantos admiradores a Gil de Biedma hace dos décadas, vemos que los versos genuinamente de esa categoría son de un porcentaje relativamente bajo, aunque son muy variados ${ }^{21}$. Esta variedad queda patente en selecciones de la estrofa inicial de cinco poemas, tomados de toda su carrera poética:

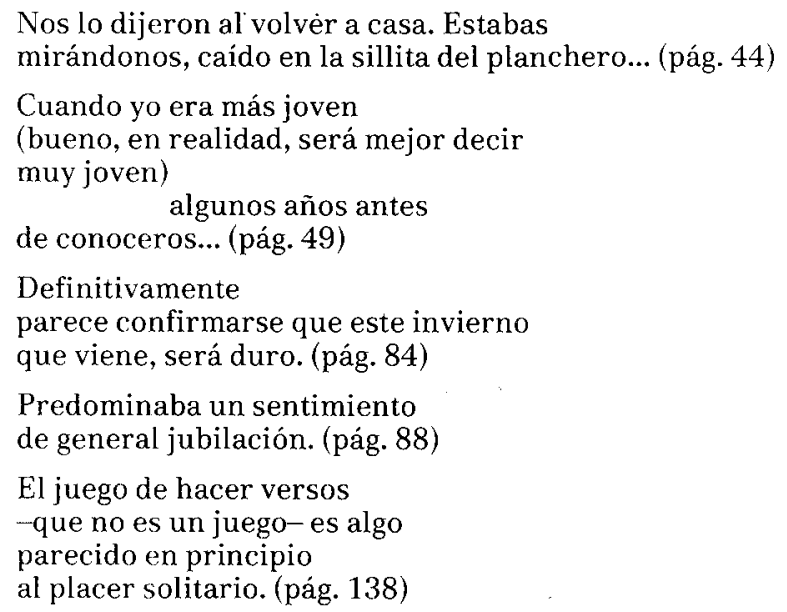

El primer ejemplo, aunque se vale de la apóstrofe tradicional, no es de ninguna manera abstracto. Por el título del poema ( $M$ Muere Eusebiom) nos situamos en una situación familiar muy concreta ante un hablante específico. Y, como sugiere Ellis arriba, es nuestro reconocimiento del contexto cultural de esta situación lo que evoca en nosotros el sobresalto que parecemos compartir con el hablante. El segundo ejemplo es mucho más jocoso; nos evoca inmediatamente el ambiente de café entre amigos. El lector, en efecto, se convierte en uno de los participantes ("antes de conoceros») $)^{22}$. Los otros ejemplos son igualmente conocidos. El tercero parece venir directamente de un programa de televisión sobre las condiciones climáticas anticipadas, el cuarto de un reportaje de eventos sociales ${ }^{23}$, y el último de una

21. No considero apropiado incluir aquí poemas donde Gil emplea voces en su función más tradicional; por ejemplo, he eliminado de mis cálculos los poemas donde el hablante se vale esencialmente de la apóstrofe (singular o plural), o de preguntas retóricas, o de citas de otros poetas, en vez de una voz concreta y personalizada.

22. Rovira, 269-270.

23. Mangini, 86. 
ponencia profesoral, por lo menos hasta que llegamos al cuarto verso.

Bien mirados, estos ejemplos evidencian que el lenguaje «oral» y el "coloquial» no son idénticos. Los primeros dos ejemplos son muestras de ambas categorías, pero el tercero viene de una fuente mucho más formalizada. Aunque se oyen frases parecidas a diario en la televisión o la radio, son de comentarios preparados de antemano para leerse en voz alta más bien que en una situación cotidiana. El cuarto ejemplo presenta otros problemas: aunque es algo que vemos todos los días en la sección social de los periódicos, y es por eso algo "cotidiano", no es de ninguna manera "oral" ni "coloquial». El último ejemplo, como se habrá adivinado, comparte el tono altisonante del cuarto. A diferencia de éste, es "oral" pero no "coloquial». Viene de una fuente aún más enrarecida: la tarima profesoral.

En todos estos poemas, la diversidad de sus fuentes incita la curiosidad del lector. Sin embargo, al entrar de lleno en los poemas correspondientes, el lector se encuentra con significados muy distintos a los que anticipaba por la introducción. El juego de perspectivas producido por este conflicto enriquece mucho la complejidad y la ambigüedad de sus reacciones y, por lo tanto, de su experiencia ${ }^{24}$. Es decir, el uso del habla «coloquial» nunca tiene sólo una función comunicativa; como vemos en todos los poetas de la segunda generación de la postguerra, el juego de lenguajes produce fines decididamente estéticos muy semejantes a la función de los juegos de tono o de las alusiones en la poesía clásica. A la vez, su ambigüedad le da a la poesía un carácter fluctuante muy característico del postmodernismo ${ }^{25}$.

Enriquece esta complejidad el hecho de que muchos poemas de Gil de Biedma no tienen nada que ver con el castellano hablado; la dificultad de la sintaxis, los juegos conceptuales y las imágenes refinadas exigen un conocimiento cultural amplio, y varias lecturas con el

24. Véase Debicki, 126-29; Jiménez, 209-215; y Mangini González, 41-47 y 77. Pedro Gimferrer comenta que la lectura de Gil de Biedma es una trampa para el lector, por sus intrigas, y para el crítico, porque resiste mucho el análisis tradicional (pág. 242).

25. Jean-François Lyotard nos proporciona un excelente análisis del papel del lenguaje de la época postmoderna en las ciencias, las artes y la filosofía en su libro La Condition postmoderne: rapport sur le savoir (Paris, Les Editions de Minuit, 1979). 
texto delante de los ojos, para actualizarse de manera adecuada ${ }^{26}$. A menudo el lenguaje es abiertamente literario, produciendo fuertes ecos intertextuales: "Pasada ya la cumbre de la vida, / justo del otro lado, yo contemplo / un paisaje no exento de belleza / en los días de sol, pero en invierno inhóspito» (pág. 144) ) $^{27}$.

Por último, hay mucha diferencia entre un castellano "hablado» y culto y otro de veras "oral», como en la tradición narrativa o en el habla callejera. En la poesía ya acostumbramos aceptar aquél, perc nos despistan toques orales. En parte es un problema de compren sión que viene de nuestro profundo descubrimiento de la organización de la realidad vigente en las culturas orales. A diferencia del texto escrito y sus convenciones, la ejecución oral, sea cotidiana o narra$\mathrm{da}$, nunca se hace dos veces exactamente igual, y no lleva esa intención. En la cultura oral, la palabra no es una cosa sino un evento, un poder mágico. Sucede en función activa y colectiva, no solitaria y más pasiva como la lectura de un texto en la biblioteca. Claro está, la ejecución oral no es capaz del pensamiento abstracto, de la clasificación de categorías, ni de la contemplación analítica que resultaron de la invención de la escritura y, de mayor importancia para nuestra cultura, la imprenta. Pero actualiza una sabiduría a base de síntesis, una belleza y un poder que nuestra cultura alfabetizada simplemente no puede reproducir ${ }^{28}$. Como nota Walter Ong en su libro Orality and Literacy, es imposible que una cultura familiarizada con la imprenta vuelva del todo a la actuación espontánea, colectivizada y sintetizadora de la tradición oral; ya dependemos demasiado de lo visual. La poesía de Celaya, de Fuertes, o de Gil de Biedma es para leerse o recitarse; nunca fue el producto de la espontaneidad e irrecuperabilidad de una ejecución oral. Y en ejemplos más extremados como la poesía concreta, una lectura oral ni siquiera es posible. Los críticos simplemente no poseemos los conceptos necesarios para tratar textos ora-

26. Masoliver Ródenas ya ha notado que "Las afueras", un poema temprano de diversas secciones, es "difícil de penetrar" y de un contexto puramente poético (pág. 16). Ya que Gil comenzó a escribir este poema en 1951 (Mangini, pág. 201), mucho antes del fin de la época "social" de la poesía de postguerra, es evidente que su itinerario literario ya tomaba otro rumbo y que le interesaba poco el de sus contemporáneos.

27. Rovira nota la semejanza con Dante (pág. 232), pero en realidad los ecos producidos por este poema aparecen en muchos poetas famosos.

28. Walter J. Ong, Orality and Literacy: the Technologizing of the Word (New York, Methuen, 1982), págs. 23-57. 
les, y por eso a menudo los evaluamos como imitaciones inferiores de los textos escritos, e indignos de la poesía auténtica.

Al mismo tiempo, Ong nota que la escritura permite la restauración de la memoria de la oralidad. Por ejemplo, de niños todos participamos en un mundo oral, aunque el dominio de las influencias escritas que nos circundan modifica mucho esta participación. Las asociaciones de ese mundo que llevamos inconscientemente en la vida adulta, a pesar de los esfuerzos de las escuelas por erradicar esas tendencias, son precisamente las que enumera Ong en las culturas orales: intimidad, colectividad, participación activa, irrecuperabilidad, magia. Las creaciones y reacciones del niño son espontáneas; por ejemplo, el niño no tiene que tratar de descifrar un drama escrito para determinar cómo se deben leer los papeles. En sus dramatizaciones los límites del texto escrito no existen ${ }^{29}$. La palabra todavía es para él una realización viva, mágica y conmovedora.

Y es más: el mundo de los cuentos de hadas y los juegos de fantasía infantiles son una parte importante de nuestra formación psicológica de adultos. A pesar de su valor esencial para nuestra civilización, el ambiente académico es una creación artificial, y por eso no conlleva la intensidad emotiva de las experiencias imaginativas de la niñez. Como nota Ellis, la literatura, el amor y el juego infantil tienen en común, no obstante una falta de valor práctico, una persistencia en toda cultura y en todo tiempo que nos comprueba su valor radical. El placer que recibimos de estas actividades, a pesar de sus complicaciones, y el contenido aumentado de nuestras experiencias por medio de ellas, tienen profundas consecuencias psicológicas en nuestras percepciones personales y sociales ${ }^{30}$.

En Gil de Biedma y en otros poetas de su generación encontramos poemas que parecen inspirarse en estas experiencias auténticamente orales de nuestra vida. Por ejemplo, Gil de Biedma emplea las dos modalidades orales mencionadas aquí: la de la narrativa oral tradicional y la de los recuerdos de la niñez. En el poema "Piazza del popolo", de Compañeros de viaje (1959), podemos ver que es la actualización de las voces de la hablante lo que produce tanto asentimiento

\footnotetext{
29. Ong, 3-15, 112-114, 102 y 164.

30. Ellis, 238-244.
} 
en el lector, y no el tema social convencional y potencialmente sentimentalizado. El poema comienza con una voz inmediatamente reconocible, pero no muy frecuente en la poesía moderna:

\author{
Fue una noche como ésta. \\ Estaba el balcón abierto \\ igual que hoy está, de par \\ en par. Me llegaba el denso \\ olor del río cercano \\ en la oscuridad. Silencio.
}

El subtítulo del poema en la página dice que «Habla María Zambrano", lo que nos revela la intención del poeta con respecto a la escritora exiliada y sus conocidas actividades políticas ${ }^{31}$. Aun para los lectores que no la conocen, su nombre evoca cierto elemento "legendario" que la coloca dentro de los significados compartidos de la comunidad mencionados por Ellis ${ }^{32}$. Pero a la vez, el poema puede funcionar al nivel universal que no depende de este conocimiento ${ }^{33}$. La voz que escuchamos al principio es la de la tradición oral narrativa, la cual nos sugiere el comienzo de un cuento o una leyenda: «Fue una noche como ésta»; "igual que hoy está». Esta impresión queda intensificada por la forma tradicional en romance del poema. Nos evoca el ambiente del cuentero o juglar, un ambiente íntimo, partícipe e intenso en que el narrador adapta su actuación a su auditorio presen$t^{34}$. Las palabras «oscuridad" y "silencio" del sexto verso añaden el

31. En Insula, núms. 458-59 (1985), 2, leemos que ha vuelto la escritora a España, la «última gran figura del exilio intelectual español».

32. Ellis, 140-142.

33. Rovira nos da las circunstancias biográficas de este poema (pág. 281) y, en mi opinión, esto restringe demasiado su interpretación. Ellis nota que la crítica basada en la biografía limita el texto a un tiempo y a una persona. Pero el autor ya ha seleccionado lo que considera importante para el poema, y eso está en el poema. Cuando aplicamos la biografia a un texto, lo sustituimos por el texto mismo y reducimos su potencial para el lector (págs. 111-134).

En el caso de una persona conocidísima como María Zambrano, el subtítulo la convierte en personaje del poema, en ente de ficción igualmente accesible a todo lector. No es diferente en este caso de una alusión cualquiera, pero sí tiene más importancia en el poema que una mera dedicatoria porque nos evoca una manera de narrar bien conocida en esta escritora. Claro está, la mención de su nombre evoca también inmediatas asociaciones personales a sus conocidos, las cuales a la vez limitan las interpretaciones del poema, mientras que el lector que no sabe de ella tiene más potencial interpretativo pero menos reacción personal. Desde luego, convienen todas estas reacciones. Esto nos muestra de nuevo el virtuosismo de Gil de Biedma en crear poemas de múltiples significados.

34. Ong, 45-46. 
elemento de suspenso palpable típico de la tradición ${ }^{35}$. El único elemento que no cabe precisamente, aunque está bien escondido, es el "denso olor del río", que parece más tópico de poema lírico que de narrativa y que nos prepara para el cambio que viene en los versos siguientes:

\author{
Silencio de multitud, \\ impresionante silencio \\ alrededor de una voz \\ que hablaba: presentimiento \\ religioso era el futuro. \\ Aquí en la Plaza del Pueblo \\ se oía latir -y yo, \\ junto a ese balcón abierto, \\ era también un latido \\ escuchando. Del silencio, \\ por encima de Ia plaza, \\ creció de repente un trueno \\ de voces juntas. Cantaban. \\ Y yo cantaba con ellos.
}

El escenario y el tono han cambiado bastante. La narradora de los primeros versos se ha convertido en espectadora de una escena que ella mira en soledad y desde cierta distancia. Pero todavía llevamos la sensación de participación íntima de los primeros versos, en parte porque esta sección del poema sigue con sus resonancias de la narración tradicional en la reiteración de la palabra "silencio" y su evocación misteriosa de la escena mediante las "voces" como entidades sin cuerpo (vv. 9 y 19). Algunos elementos sugieren más un momento introspectivo de parte de la hablante («presentimiento / religioso era el futuro; y yo, / ...era también un latido escuchando»), pero no dominan. Su integración al grupo se destaca más que su aislamiento.

Por eso, cuando llegamos al verso 19 («voces juntan. Cantaban») estamos preparados para asentir con el hecho de que ella se une a los otros en su canción sin saber nosotros de qué se trata, y hasta con los excesos retóricos que siguen: "Oh si, cantábamos todos / otra vez, qué movimiento, qué revolución de soles en el alma!» (vv. 21-24). Esta voz es más típica de la de la poesía social, y se podría convertir

35. Ong comenta varias características de la actualización oral que se sugieren en esta selección: la presencia de seres sobrenaturales y el ambiente partícipe (pág. 45), la naturaleza situacional y no abstracta del texto (pág. 49), y los personajes unidimensionales en circunstancias extravagantes (pág. 70). 
fácilmente en exceso romántico, demasiado grandilocuente para este contexto. Pero dentro del marco de una percepción individual, expresada por medio de una narración «oral» de la anécdota, sí cabe. Dramatiza auténticamente uno de los muchos íntimos sentimientos contradictorios de esta persona ficticia pero concreta delante de la cual nos encontramos, a la vez que los esfuma con sus rasgos «heroicos»"

En los versos siguientes experimentamos el mismo vaivén entre la voz narradora, más generalizada, y la personalizada, emocionada. Llegamos a conocer la base anecdótica que produjo su reacción exagerada. La canción de la plaza le recuerda las otras canciones en que ella cantaba con sus amigos:

\section{Sonrieron}

rostros de muertos amigos

saludándome a lo lejos

borrosos -pero qué jóvenes, qué jóvenes sois los muertos!y una entera muchedumbre me prorrumpió desde dentro toda en pie.

El poema ha logrado fundir una característica de la tradición oral, el argumento hecho de acontecimientos heroicos, y otra de la tradición literaria moderna, la introspección ${ }^{37}$, para evocar un momento intensamente personal como si fuera hazaña de epopeya. La yuxtaposición sobre este momento de las reuniones públicas de los días de esperanza ya pasados, y de las muertes de la guerra ("borrosos -qué jóvenes, / qué jóvenes sois los muertos!-»), dramatiza eficazmente la mezcla de regocijo y de dolor que la hablante experimenta al recordar a los suyos. La naturaleza precisa de sus actividades politicas, por lo tanto, importa aquí mucho menos que la memoria de las relaciones interpersonales creada en la estructura del poema. Esta evoca gráficamente el ambiente provisional pero intensamente compartido en que los republicanos en fuga habrían tenido que contarse sus historias, por necesidad de carácter oral. En el poema este estímulo, a su vez, transforma la noche solitaria:

36. Rovira nota que la exaltación del poema se produce mediante una voz callada (pág. 283).

37. Ong, 105 y $139-40$. 
Bajo la luz

de un cielo puro y colérico

era la misma canción

en las plazas de otro pueblo,

era la misma esperanza,

el mismo latido inmenso

de un solo ensordecedor

corazón a voz en cuello.

Sí, reconozco esas voces

cómo cantaban. Me acuerdo.

Aquí en el fondo del alma

absorto, sobre lo trémulo

de la memoria desnuda,

todo se está repitiendo.

Cabe mencionar aquí que la descripción de los dos grupos, el de la plaza y el de las memorias, contiene poco detalle. Importa más la actualización en el lector del pensar personalizado de esta determinada hablante; no es ni necesario ni importante que sepamos más de sus camaradas. La experiencia básica humana comunicada evocará diferentes momentos para diferentes lectores, pero la experiencia psicológica de la funcíon de la memoria será muy semejante para todos.

En el resto del poema crece la sensación de gran momento, en parte por la continuación del ritmo reiterativo de la tradición oral en los versos 33-36 ("era la misma») que imita el impulso unificador de los primeros versos del poema ("una noche como ésta»; "igual que hoy está»). Pero esta vez, en lugar de incluir detalles concretos para conceder credibilidad a la narración, como en la tradición oral, se evoca su visión de la plaza en su forma transformada, confirmando la relación con otros tiempos mediante la credibilidad ya establecida de la hablante. El poema, entonces, comienza con una situación concreta como si fuera fondo de narración fantástica; el resto del poema presenta los vuelos de la memoria casi como datos de testimonio legal («Era la misma canción»; "Sí, reconozco»; "me acuerdo», vv. 33-40). Para la hablante, claro está, sus recuerdos llevan una intensidad mucho más viva que la realidad que ahora presencia ${ }^{38}$. Estos recuerdos también sirven para evocar otros, expresados con igual falta de detalle e igual intensidad emotiva:

38. El artículo de Debicki estudia en otros poemas cómo la ilusión, creada artificiosamente por el poeta mediante sus hablantes, a menudo socava y extiende los significados de la realidad que parecen tan claros y directos en la superficie. Sus estudios lo llevan a la conclusión de que en Gil de Biedma la ilusión es la única realidad que importa. 


\begin{abstract}
$\mathrm{Y}$ vienen luego las noches interminables, el éxodo por la derrota adelante, hostigados, bajo el cielo que ansiosamente los ojos interrogan. $Y$ de nuevo alguien herido, que ya le conozco en el acento, alguien herido pregunta, alguien herido pregunta en la oscuridad. Silencio.
\end{abstract}

El poema aquí se vuelve circular. Las reiteraciones de los versos 46-49 evocan el estilo de la narración oral, y el verso cincuenta repite exactamente el verso seis. La narración angustiada ha terminado. Pero no los efectos personales sobre la narradora actual:

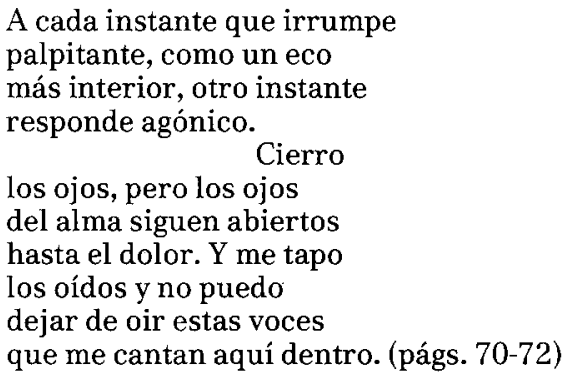

El final del poema utiliza varios clisés de la tradición literaria («eco más interior»; «los ojos del alma»; "voces que me cantan aquí dentro"). En realidad, la voz de esta última parte la anticiparíamos en un poema más convencional. Pero por la modificación que el poema ha realizado anteriormente, podemos compartir su sentimiento personalizado de pérdida, con todo el pánico correspondiente y toda la riqueza de su estado anímico, sin caer en el sentimentalismo. Este sentimiento no depende de las circunstancias biográficas del poeta (no importa, por ejemplo, que la canción sea la Internacional, aunque esto será clave para ciertos lectores), sino que está ya al alcance de toda la sociedad. Los seres de su memoria han cobrado perfil heroico, y aun los "instantes" de su vida luchan como protagonista y agonista (vv. 51-54). El poema crea gráficamente para nosotros una experiencia básica humana, patrimonio de muchas épocas. Pero es su manipulación de convenciones culturales específicas, muchas de ellas orales, lo que ha creado el contexto necesario para nuestra apropiación psicológica personal de ella. 
Uno de los poemas más conocidos de Gil de Biedma es «Intento formular mi experiencia de la guerra", de Moralidades (1966), en parte por su tratamiento inusitado de este tema y en parte por su renovación de la postura testimonial de la primera generación de la postgue$\mathrm{rra}^{39}$ :

Fueron, posiblemente,

los años más felices de mi vida, y no es extraño, puesto que a fin de cuentas no tenía los diez.

Como nota Rovira, el tema no es la guerra, «sino su personaje poético en relación con ella, una relación doble: la del niño y la del adulto". Pero queda implícito el hecho de que otros niños no lo pasaban tan bien en esos años, que los años sólo podrían ser "felices" para un "vástago de familia acomodada». Esto se nos presenta en la perspectiva del adulto que contempla su propia niñe ${ }^{40}$.

Otra vez podemos ver que el hablante posee varias voces, cada una con resonancias culturales muy específicas. Los primeros dos versos evocan fuertes ecos de las "historias" de un viejo que recuerda sus años en la universidad, en su primer trabajo o con su mujer, tal vez en la celebración de su aniversario de matrimonio o su fiesta de jubilación. Forman una frase trillada que nos coloca inmediatamente en un ambiente de vieja amistad cómoda, de lo conocido. El tercer verso sigue por este rumbo con otro lugar común ("puesto qué a fin de cuentas"). Pero en el cuarto verso todo se cuestiona. Pocos viejos suelen considerar una edad menor de "los diez" como la época cumbre de la vida; en realidad, pocos se acuerdan mucho de esos años. El verso nos despista, y en vez de aceptar abiertamente como antes, nos ponemos a examinar, y a evaluar ${ }^{41}$. ¿Es un viejo el que recuerda, o es un adolescente? En todo caso, el hablante de repente nos parece más borroso y menos digno de confianza.

La segunda estrofa empieza con otro lugar común, algo que se habría dicho a menudo durante la guerra civil española, aunque es común a todas. Esta vez, sin embargo, cambia en otra voz muy diferente:

39. Rovira, 150-152 y 289-294; Persin, "Intertextual Strategies".

40. Rovira, 289-291.

41. Debicki nota esta misma tendencia de la obra de Gil de Biedma en otro contexto; véase las págs. 124-125. 
Las víctimas más tristes de la guerra
los niños son, se dice.
Pero también es cierto que es una bestia el niño:
si le perdona la brutalidad
de los mayores, él sabe aprovecharla
y vive más que nadie
en ese mundo demasiado simple,
tan parecido al suyo.

En contraste con la primera estrofa que mira la niñez con nostalgia, ésta presenta dos perspectivas negativas: la guerra y sus efectos, y el carácter bestial del niño. Los versos 5-6 parecen compadecerse de los niños. Pero es la voz de los versos 7-12 la que crea la riqueza y la ambigüedad. No es difícil identificarla como la de un pariente mayor que odia a los niños "mimados" y justifica su actitud mediante un "análisis» más o menos clínico ante los padres. Podemos experimentar, entonces, la lucha del hablante consigo mismo. Desea creer que en su juventud él fue tan víctima de la guerra como los otros niños (vv. 5-6). Pero ya no puede creerlo. Las dos voces, que este hablante ficticio habría "oído" (y comprendido poco) en su juventud, dramatizan su conflicto de una manera muy concreta. El adulto puede ahora analizarlas como símbolos contrarios de su pasado vergonzoso.

La parte central, como ya ha notado Rovira, desarrolla una serie de escenas donde pasó el hablante su aprendizaje de hombre durante los años de la guerra: «el descubrimiento del paisaje, el carácter mítico que adquiere la pequeña ciudad de provincias, Segovia, y las imágenes rescatadas de una excursión a un pueblo vecino». Son más bien sensaciones que hechos, con "cambios de tono que nos van recordando que alguien narra, que hay una superposición de puntos de vista, y nos van distanciando para apreciar no lo que el niño ve o siente, sino al niño vivo y sintiendo". Existen claras distinciones entre la voz de un narrador que usa el vocabulario maduro, y pequeñas muestras de la mentalidad juvenil apoyadas en un sentido de experiencia común a todos los niños: "buscábamos la arena removida / donde estaban, sabíamos, los cinco fusilados»; "los discursos / ...nos ofrecían / un billete de vuelta al siglo diez y seis» (vv. 34-35, 48-51) ${ }^{42}$.

Otras voces o muestras intensifican esta distinción, aunque no todas son de índole oral. Una voz romántica idealiza las circunstan- 
cias de un modo que ningún niño emplearía: «y las tardes de azul, celestes y algo pálidas, / con los montes de nieve sonrosada a lo lejos"; "una de esas mañanas que la luz / es, aún, en el aire, relámpago de escarcha, / pero que anuncian ya la primavera" (vv. 16-47, 40-42). En cambio hay otra, que por el vocabulario y la fascinación por ciertos detalles actúa la perspectiva típica del niño que "no tenía los diez»; "fue conocer los páramos con viento, / Ios sembrados de gleba pegajosa»; "Segovia / ...era ya casi el frente / -o por lo menos un lugar heroico, / un sitio con tenientes de brazo en cabestrillo" (vv. 14-15, 26-29). Tanto la "gleba" como la guerra son parte de un gran juego.

Estas contradicciones encarnan las que siente el mismo hablante al contemplar su niñez, revelando para el lector al niño que todavía reside en el adulto y las voces que todavía oye de su pasado. La mezcla de lenguaje romántico y de aventura juvenil produce en nosotros también un pretexto para poder asentir con su evaluación: «¿Qué niño no lo acepta?» (v. 52). Podemos evadir la lección austera de la primera parte del poema que acusa al niño de «aprovechar" la «brutalidad de los mayores" y «ese mundo demasiado simple / tan parecido al suyo" (vv. 7-12).

El final del poema evita esa resolución sencilla sin descartar tampoco la honda verdad que el hablante ve en su niñez:

Cuando por fin volvimos

a Barcelona, me quedó unos meses

la nostalgia de aquello, pero me acostumbré.

Quien me conoce ahora

dirá que mi experiencia

nada tiene que ver con mis ideas,

y es verdad. Mis ideas de la guerra cambiaron

después, mucho después

de que hubiera empezado la postguerra. (págs. 122-124)

En la interpretación de Rovira, esta parte sirve para mostrarnos que la poesía viene de las experiencias y no de las ideas ${ }^{43}$. De esto no cabe duda. Pero el final del poema también nos muestra, en forma de idea, la experiencia realizada en el resto del poema: los años de la ninez imprimen en nuestra subconsciencia una matriz interpretativa de la realidad que ni el adolescente ni el adulto puede suprimir del todo. Otra vez, un poema producido en circunstancias históricas muy

43. Rovira, 289 y 294. 
precisas ha logrado meternos en un conflicto básico a todo ser humano mediante su evocación de las perspectivas típicas de las voces que imita y el contexto cultural donde cobran vida.

Se ha comentado el cambio gradual de la voz más típica de Gil desde una más característica de la adolescencia, incierta de sí misma, en Compañeros de viaje, a otra más confiada y madura en Moralidades, y finalmente a la más introspectiva de la vejez en Poemas póstumos $(1968)^{44}$. Esto naturalmente resulta en un número reducido de voces orales externas en Poemas póstumos, pero no de las internas. Esto se verá en otro ejemplo de lo aferrada que está nuestra juventud a nuestra subconsciencia, en el poema "Contra Jaime Gil de Biedma", de Poemas póstumos:

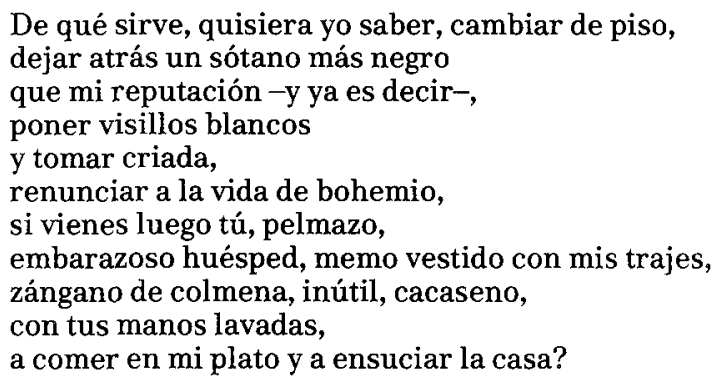

La profesora Persin ha indicado con mucha perspicacia cómo la indeterminación semántica de la caracterización de este hablante, mediante la batalla del lenguaje por resolverse, reproduce la batalla entre las varias facetas de un solo hablante que sólo reconocemos al final del poema. Al comenzarlo no sabemos si hablan viejos amigos, si un padre le habla a su hijo, o si son amantes; en realidad hay elementos lingüísticos que podrían autorizar cualquiera de estas interpretaciones $^{45}$.

Pero ¿por qué este poema nos arrastra tan de golpe a su mundo ficticio? En mi opinión, es en parte porque el poema juega tan deliberadamente al nivel oral. Comienza en medias res con una disputa claramente familiar. No sabemos si habla hombre o mujer, aunque algunos elementos (sótano negro, visillos blancos, tomar criada) parecen

44. Véanse, por ejemplo, Mangini González, 90 y 107-109, y Rovira, 79-97, 118-119, 206-209 y $217-240$.

45. «Self as Other in Jaime Gil de Biedma's Poemas póstumos" (Anales de la literatura española contemporánea, en prensa). 
indicar que es mujer. El verso siguiente, al contrario, tiene resonancias masculinas: "renunciar a la vida de bohemio». Sigue una lista de imprecaciones que también parece vacilar en cuanto al género y a la edad del hablante y del increpado: "memo vestido con mis trajes»; "zángano de colmena"; "cacaseno" ${ }^{46}$; "vienes... a comer en mi plato y a ensuciar la casa". La antítesis de los vv. 10-11 («manos lavadas/...a ensuciar la casa») hace más compleja la caracterización del «embarazoso huésped», sugiriendo rasgos de la conducta infantil. Presenciamos los antagonismos de las relaciones familiares de una manera poco acostumbrada en la poesía. Y, en realidad, si este poema se hubiera escrito de una forma más "poética», no nos intrigaría tanto. A todos nos gusta ser voyeristas de tales disputas, especialmente a escondidas. La vergüenza sólo sirve para aumentar nuestra curiosidad:

Te acompañan las barras de los bares

últimos de la noche, los chulos, las floristas,

las calles muertas de la madrugada

y los ascensores de luz amarilla

cuando llegas, borracho,

y te paras a verte en el espejo

la cara destruída,

con ojos todavía violentos

que no quieres cerrar. Y si te increpo,

te ríes, me recuerdas el pasado

y dices que envejezco.

Aqquí, al enfocarse en los excesos alcohólicos del huésped, el lenguaje toma un carácter más imaginativo: «Te acompañan las barras de los bares / ...las calles muertas de la madrugada". Este es el primer lenguaje "literario" que hemos encontrado en el poema; nos caracteriza a un hablante culto, lo cual cuestiona la introducción oral y nos prepara para aceptar un tratamiento metafórico. Pero éste no viene

46. Cacaseno: individuo simple o bobo, por alusión al personaje del mismo nombre de la novela Bertoldo, Bertoldino y Cacaseno de Julio César della Croce (Enciclopedia Universal Sopena: Diccionario ilustrado de la lengua española, Barcelona, Editorial Ramón Sopena, 1969, pág. 1.478). El texto original de Croce (1550-1609), adicionado con la Novella di Cacasseno por Camilo Scaliggeri della Fratta (Adriano Banchieri, m. 1634), fue escrito de nuevo en verso y prosa por autores de varios siglos y traducido a muchas lenguas hasta mediados del siglo XX (National Union Catalog: Pre-1956 Imprints, tomo 127, Londres, Mansell Information/Publishing Ltd., 1971, págs. 440-442). Llegó a ser «una popularísima narración infantil» (José Antonio Pérez-Rioja, Diccionario Literario Universal, Madrid, Editorial Tecnos, 1977, pág. 260). El carácter ingenuo del personaje novelesco, su fama entre los escritores y lectores cultos y populares, adultos y niños, y la crudeza del sentido literal de su nombre, hacen que este vocablo funcione en varios niveles según los conocimientos del lector y el desarrollo del poema. 
como anticipamos; en su lugar volvemos al abuso verbal (vv. 17-18). Obviamente los dos se conocían antes, pero todavía es difícil reconocer la relación:

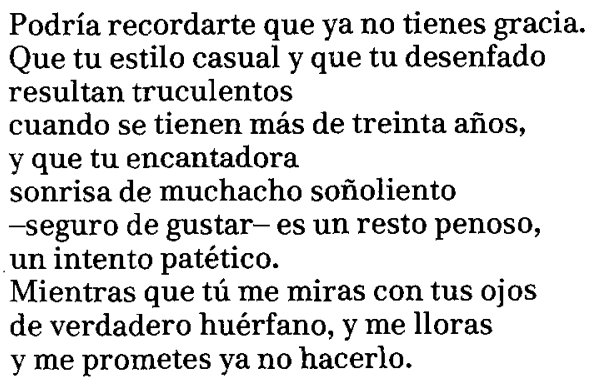

El complejo verbal se enreda. El hablante parece ser el padre del borracho, reprendiéndole su conducta inapropiada "cuando se tienen más de treinta años» (v. 26). Pero al mismo tiempo hay elementos que recuerdan el contexto infantil de la primera estrofa (vv. 27-29, 31-32). Gradualmente nos damos cuenta de que tenemos aquí una fuerte semejanza con la situación entre dos hermanos, uno menor que sigue siendo «bohemio» y el otro, el mayor, que se ha adaptado a la vida doméstica. Por experiencia, el hermano «burgués» a la vez increpa y quiere al otro; recuerda el efecto de su "sonrisa de muchacho soñoliento" (habría sido el niño mimado de la familia) a la vez que se da cuenta de la imposibilidad de volver al pasado: "me miras con tus ojos / de verdadero huérfano, y me lloras / y me prometes ya no hacerlo" (vv. 31-33). El hermano hablante ya le es tanto padre como madre al borracho; por eso la primera parte combina características de los dos. Esto puede explicar también la alternancia entre adulto y muchacho en sus relaciones; encarna también incidentes de su juventud cuando los papeles se imitaban pero no se habían fijado todavía.

En las últimas estrofas el hablante sigue por este mismo rumbo, mostrando su odio tanto como su dependencia de él:

;Si no fueses tan puta!

Y si yo no supiese, hace ya tiempo, que tú eres fuerte cuando yo soy débil y que eres débil cuando me enfurezco...

De tus regresos guardo una impresión confusa

de pánico, de pena y descontento,

y la deseperanza

y la impaciencia y el resentimiento

de volver a sufrir, otra vez más,

la humillación imperdonable

de la excesiva intimidad. 


\begin{abstract}
A duras penas te llevaré a la cama, como quien va al infierno

para dormir contigo.

Muriendo a cada paso de impotencia, tropezando con muebles

a tientas, cruzaremos el piso

torpemente abrazados, vacilando

de alcohol y de sollozos reprimidos...
\end{abstract}

La última estrofa se ha interpretado como una escena erótica ${ }^{47}$. La posibilidad claramente existe, pero ¿no es posible, también, dado el contexto, que los hermanos se vayan a consolar como cuando eran niños? Esto podría producir "pánico" en un hombre mayor (vv. 41-44), convencido de la impropiedad de cierta "intimidad" dentro de su mentalidad burguesa pero a la vez convencido de su mutua necesidad. La estrofa termina con una escena conmovedora en que el hablante y el otro, "vacilando / de alcohol y de sollozos reprimidos", tropiezan contra los muebles al tratar de llegar a su cámara.

Y luego, en el momento en que creemos que hemos resuelto las contradicciones del poema, todo se hunde. Nos enteramos de que los dos personajes son en realidad una sola persona ${ }^{48}$ :

Oh innoble servidumbre de amar seres humanos, y la más innoble

que es amarse a sí mismo! (págs. 145-146)

El título del poema nos lo dice desde el principio, pero la profunda situación humana encarnada en los diferentes idiomas orales nos intriga tanto que nos desvía. Los ecos de disputas familiares entre hermanos, esposos o padres e hijos vienen de los muchos recuerdos del hablante, y producen una riqueza de efectos que un idioma más "literario", en el sentido tradicional, no lograría. Este poema encarna de una manera muy concreta, entonces, la lucha entre los papeles de

47. Véanse Mangini González, 92 y Masoliver Ródenas, 18 y 20 . Otra vez la interpretación demasiado biográfica limita las interpretaciones posibles.

48. Debicki, 138-139; Mangini González, 91-94. Pere Rovira insiste que no es un truco, que el lector sabe desde la lectura del título del poema que el tema es el del doble, y que «la comprensión del poema pasa precisamente por no caer en la trampa de la "riña entre amantes"" que sugiere Mancini. Para Rovira el poema gira alrededor del juego entre "regresado" e uincrepador" que desde el primer momento del poema son el mismo personaje (313-319). Las dos versiones son posibles, a mi modo de ver, pero ninguna hace mención del profundo carácter oral de las voces. 
bohemio y poeta, y de burgués, que Masoliver Ródenas nota como el tema predominante de toda la obra de Gil de Biedma ${ }^{49}$.

Claramente, estas técnicas no son exclusivas de la poesía de Gil de Biedma; Nancy Mandlove y Santiago Daydí-Tolson han estudiado parecidos elementos orales en la obra de Gloria Fuertes y Angel Gonzále $z^{50}$. Está claro también que las diferencias entre las culturas orales y las alfabetizadas no son tan grandes en su manera de apropiar otros textos. Si el narrador oral utiliza fragmentos ya hechos a lo largo de siglos, y crea innovaciones en el acto de recombinarlos y adaptarlos a la situación ${ }^{51}$, el poeta utiliza también textos ya hechos, sean literarios u orales, y los adapta a las necesidades de su poema. Cada tradición tiene su propia manera de ser original, y su manera de utilizar resonancias ya existentes. En la poesía española, esta doble fuente sólo alcanza su potencialidad con la segunda generación de la postguerra. Es evidente, por ejemplo, que Gil de Biedma no se contenta con introducir un lenguaje "cotidiano" por las mismas razones que hemos comentado en el grupo de los años cincuenta. El fin es estético, nacido de necesidades poéticas, y no otro. Si éste es el legado de la poesía social de la postguerra, aun sin intención, no podemos dejar de reconocer que ha multiplicado inmensamente el arsenal de la poesía en su búsqueda de nuevas armas para ofrecer al lector experiencias humanas básicas.

John Ellis define la literatura, basándose en conceptos de Wittgenstein, en términos de su función en vez de sus atributos: la literatura es el trozo de lenguaje que la comunidad utiliza como literatura; es decir, divorciado de la relevancia al contexto inmediato de su producción y de la necesidad de llevar a cabo algún propósito específico. No la usamos principalmente para conseguir información ni para determinar si es cierta o falsa, sino para aumentar nuestra experiencia de la vida; por eso no importa qué clase de lenguaje adopta un texto; si la sociedad acepta ese texto como literatura, lo define como tal. Si decide usar un texto como historia, o como biografía, o como docu-

\footnotetext{
49. Masoliver, 22.

50. Mandlove, «Oral Texts: The Play of Orality and Literacy in the Poetry of Gloria Fuertes"; Daydi, "Oralidad y escritura en la poesía de Angel González", ambos estudios en Siglo $X X / 20$ th Century, en prensa el segundo en el n. ${ }^{\circ} 6$, el primem en el n. ${ }^{\circ} 5$ (1987-88, 1-2, pp. 11-16).
}

51. Ong, 32-35. 
mento social, eso es asunto aparte. Siempre hay nuevas formas para considerar, porque siempre hay nuevos textos. Pero las funciones de la literatura en la sociedad serán iguales. La comunidad decidirá si el texto sirve según sus significados culturales compartidos, no el autor y sus intenciones ${ }^{52}$.

52. Ellis, 19-47. 